Interactive comment on "An investigation of carbon cycle dynamics since the Last Glacial Maximum: Complex interactions between the terrestrial biosphere, weathering, ocean alkalinity, and $\mathrm{CO}_{2}$ radiative warming in an Earth system model of intermediate complexity" by $\mathrm{C}$. $\mathrm{T}$.

\title{
Simmons et al.
}

U. Mikolajewicz (Editor)

uwe.mikolajewicz@mpimet.mpg.de

Received and published: 16 June 2016

Dear Dres. Simmons, Mysak, and Matthews, 
has been seen by two reviewers. Both reviewers agree that the results presented are clearly worth publishing, but had some suggestions how to improve the presentation, which also after my opinion was not as clear as it could/should be.

Especially Dr. Brovkin suggested a major reorganisation of the text. The changes you suggested to do in your reply to the reviewer's comment should after my opinion improve the presentation quality significantly. I encourage you to revise the ms. along the lines suggested in your reply. The revised ms. will be sent to reviewers.

\section{Sincerely Yours}

Uwe Mikolajewicz

minor points

- Figs. 2,3,6,7 Please use carbon densities! This would allow easy comparison with other models. The use of a quantity integrated over the model boxes is highly resolution dependent and particularly unhelpful in case of an irregular grid.

- increase of zonal wind stress in the subtropics. Is this effect also observed in more complex models, e.g. in the transient deglacial simulation of the NCAR model (Liu et al. 2009)? Please compare your model response to the results of more complex models.

Liu et al., Science 325 , 310 (2009); DOI: 10.1126/science.1171041

Interactive comment on Clim. Past Discuss., doi:10.5194/cp-2016-24, 2016.

Interactive

comment

\section{Discision paper}

